\title{
Expression of concern: A comparison between collaborative and single surgeon approach in endoscopic endonasal surgery to sphenoid sinus
}

\author{
Mostafa Ismail ${ }^{1}$ • $\cdot$ Ahmed A. Abdelaziz ${ }^{1} \cdot$ Mohab Darwish $^{2}$ \\ Published online: 17 April 2020 \\ ○) Springer-Verlag GmbH Germany, part of Springer Nature 2020

\section{Expression of concern: European Archives of Oto-Rhino-Laryngology (2019) 276:1095-1100 https://doi.org/10.1007/s00405-019-05305-y}

The Editors-in-Chief would like to alert readers that concerns have been raised that the data used in the original article belong to the University Hospital in Brussels and that authorization to use this data for publication was not given. The journal has conducted an investigation in accordance with the Committee on Publication Ethics (COPE) guidelines. Unfortunately, we have not been able to confirm or refute whether the data were collected at the University Hospital in Brussels or at Minia University Hospital or whether appropriate authorization to use the data was given. The matter is currently under investigation by the Ethics Committee of the University Hospital in Brussels and the ENT division of the Medical School at Minia University. Consequently, readers are advised to interpret the details of this article with caution. The authors Mostafa Ismail, Ahmed A. Abdelaziz and Mohab Darwish do not agree to this editorial expression of concern.

Publisher's Note Springer Nature remains neutral with regard to jurisdictional claims in published maps and institutional affiliations.
Mostafa Ismail

mostafaismail3730@yahoo.com

Ahmed A. Abdelaziz

ahmed.abdelaziz@mu.edu.eg

Mohab Darwish

mohab.darwish@mu.edu.eg

1 Department of Otorhinolaryngology, Minia University Hospital, Minya, Egypt

2 Department of Neurosurgery, Minia University Hospital, Minya, Egypt 